\title{
EXISTENCE OF POSITIVE SOLUTIONS FOR A FOURTH ORDER DIFFERENTIAL INCLUSION
}

\author{
DANIEL C. BILES AND JOHN S. SPRAKER
}

Abstract. We prove an existence result for positive solutions of a fourth order differential inclusion. The proof is accomplished through the use of Green's functions and a fixed point theorem. One of the technical assumptions is explored in detail.

Mathematics subject classification (2010): 34B18, 34A34, 34A36, 34A60, 34B15, 34B27, 47H10. Keywords and phrases: existence of solutions, fourth order, differential inclusion, fixed point, boundary value problem, Green's function.

\section{REFERENCES}

[1] R. P. Agarwal, Focal Boundary Value Problems for Differential and Difference Equations, Mathematics and Its Applications, \#436, Kluwer Academic Publishers, Dordrecht, 1998.

[2] M. Aitalioubrahim, On fourth-order boundary-value problems, Acta Univ. Palacki. Olomuc., Fac. Rer. Nat. Mathematica, 49 (2010), 5-16.

[3] A. Arara, M. Benchohra, S. K. Ntouyas, A. OuAhab, Existence results for boundary value problems for fourth-order differential inclusions with nonconvex valued right hand side, Archivum Mathematicum (Brno), 40 (2004), 219-227.

[4] R. Avery, J. Henderson, D. O'Regan, Functional compression-expansion fixed point theorem, Electronic Journal of Differential Equations, 2008 (2008), 1-12.

[5] M. El-Shahed, T. Al-Dajani, Positive solutions for fourth order boundary value problems, Int. Journal of Math. Analysis, 2 (2008), 1281-1286.

[6] J. JI, B. YANG, Positive solutions for a fourth order nonlinear boundary value problem, Proceedings of Neural, Parallel and Scientific Computations, 4 (2010), 169-173.

[7] Y. LI, Positive solutions of fourth-order boundary value problems with two parameters, J. Math. Anal. Appl., 281 (2003), 477-484.

[8] D. O'REgAN, Integral inclusions of upper-semicontinuous or lower-semicontinuous type, Proc. Amer. Math. Soc., 124 (1996), 2391-2399.

[9] D. Repovs, P. V. Semenov, Continuous Selections of Multivalued Mappings, Springer, 1998.

[10] W. SHEN, Existence of nodal solutions of a nonlinear fourth-order two-point boundary value problem, Boundary Value Problems 31, 2012.

[11] M. SvEC, Periodic boundary value problem for fourth order differential inclusions, Arch. Math. (Brno), 33 (1997), 167-171.

[12] J. R. L. WebB, G. Infante, D. Franco, Positive solutions of nonlinear fourth order boundary value problems with local and nonlocal boundary conditions, Proceedings of the Royal Society of Edinburgh A, 138 (2008), 427-446.

[13] B. YANG, Positive solutions for a fourth order boundary value problem, Electronic Journal of the Qualitative Theory of Differential Equations, 3 (2005), 1-17. 